\title{
ANATOMICAL STUDY OF FORAMEN VESALIUS
}

\author{
Gyanaranjan Nayak1, Sujita Pradhan², Sitansu Kumar Panda3, Prafulla Kumar Chinara ${ }^{4}$
}

${ }_{1}^{1}$ Associate Professor, Department of Anatomy, IMS and SUM Hospital, Siksha 'O' Anusandhan (Deemed to be University), Bhubaneswar, Odisha, India.

2Tutor, Department of Anatomy, IMS and SUM Hospital, Siksha 'O' Anusandhan (Deemed to be University), Bhubaneswar, Odisha, India. 3Professor, Department of Anatomy, IMS and SUM Hospital, Siksha 'O' Anusandhan (Deemed to be University), Bhubaneswar, Odisha, India.

4Professor, Department of Anatomy, IMS and SUM Hospital, Siksha 'O' Anusandhan (Deemed to be University), Bhubaneswar, Odisha, India.

\section{BACKGROUND}

ABSTRACT

Foramen Vesalius or emissary sphenoidal foramen is a variant foramen in middle cranial fossa and connects the pterygoid venous plexus with cavernous sinus by an emissary vein, which passes through it. This can serve as a probable route of spread of infection from facial vein and other extracranial veins to the cavernous sinus.

\section{MATERIALS AND METHODS}

The descriptive study included thirty dried, adult human skulls of unknown age and sex. They were studied macroscopically for the presence of foramen Vesalius. The maximum diameter of the foramen was measured using digital Vernier calliper. The distance of Foramen Vesalius from ipsilateral foramen ovale was measured as well. The shape of the foramen was also noted.

\section{RESULTS}

The incidence of foramen Vesalius was found to be $30 \%$ in the current study ( $20 \%$ bilateral and $10 \%$ unilateral). The mean maximum diameter of foramen Vesalius was found to be $1.13 \pm 0.30 \mathrm{~mm}$ on the right side and $1.38 \pm 0.33 \mathrm{~mm}$ on the left side. The average distance of foramen Vesalius from ipsilateral foramen ovale was determined to be $1.42 \pm 0.19 \mathrm{~mm}$ on the right side and $2.17 \pm 0.28 \mathrm{~mm}$ on the left side. All the foramina in the study were irregular in shape.

\section{CONCLUSION}

The findings of the study will be vital in anatomy, anthropology and surgical practice.

\section{KEY WORDS}

Emissary Vein, Foramen Vesalius, Cavernous Sinus Thrombosis.

HOW TO CITE THIS ARTICLE: Nayak G, Pradhan S, Panda SK, et al. Anatomical study of foramen vesalius. J. Evolution Med. Dent. Sci. 2018;7(35):3847-3850, DOI: 10.14260/jemds/2018/862

\section{BACKGROUND}

Foramen Vesalius (Emissary Sphenoidal Foramen) is an inconstant foramen of skull. It is located anteromedial to foramen ovale and lateral to foramen rotundum in middle cranial fossa.[1] This foramen opens on the base of skull lateral to scaphoid fossa. It gives passage to an emissary vein that connects cavernous sinus with pterygoid venous plexus and a nerve known as 'Nervoulus sphenoidalis lateralis.' Accessory meningeal artery may pass through the foramen in $20 \%$ cases. The emissary vein passing through the foramen is called 'Vein of Vesalius.' The vein establishes a connection between extracranial veins and intracranial dural venous sinuses. So septic thrombus may pass to intracranial venous sinuses from extracranial source. The source of infection may be from orbit, paranasal sinuses or upper half of face (The so called 'dangerous area of face'). Such septic thrombus can reach cavernous sinus resulting in cavernous sinus

'Financial or Other Competing Interest': None.

Submission 03-07-2018, Peer Review 10-08-2018,

Acceptance 16-08-2018, Published 27-08-2018.

Corresponding Author:

Dr. Gyanaranjan Nayak,

At-Flat-No-111, Manorama-Metro Complex,

Malasahi, Mangalabag, Cuttack-753001,

Odisha, India.

E-mail: drgrn82@gmail.com

DOI: $10.14260 /$ jemds $/ 2018 / 862$ thrombosis. This gives rise to severe pain along the distribution of ophthalmic division of trigeminal nerve. Trismus can occur due to involvement of mandibular nerve.[2] The emissary veins are usually valveless. They maintain balance between extracranial and intracranial venous pressure. Under normal conditions, little blood flows through them. But in cases of increased intracranial tension, they become a major route of drainage of blood.[2] Trigeminal neuralgia is a neurological condition which manifests as unbearable pain along the distribution of trigeminal nerve, particularly its ophthalmic division. Trigeminal neuralgia is treated surgically by microvascular decompression. In microvascular decompression, the needle is introduced through foramen ovale. If the needle accidentally passes into foramen Vesalius, the consequences can be catastrophic due to resultant injury to cavernous sinus. ${ }^{[2,3,4]}$ It can lead to temporal lobe haematoma. Thus, the knowledge of foramen Vesalius is significant in anatomy. It is also important in neurosurgical approach of middle cranial fossa.

\section{Objective}

To find the incidence and to do the morphometric analysis of foramen Vesalius.

\section{MATERIALS AND METHODS}

The current study was a descriptive study, carried out in the Department of Anatomy of a Medical College in Eastern India. 
The objective of the study was to find out the incidence of foramen Vesalius, its dimensions and its location from nearby anatomical landmark. The bones were used to teach osteology in routine MBBS practical classes. The study sample included thirty dry, adult human skulls of unknown age and sex. Deformed, broken skulls and those with pathological changes were excluded from the study. Skulls with broken bones around the foramen were also excluded from the study. The skulls were studied macroscopically to find out the presence of foramen Vesalius and the incidence was noted. A thin, blunt metallic probe was passed through each foramen to ensure its patency. Only those foramina which allowed the probe to pass through them were counted for incidence. The maximum diameter of the foramen Vesalius was measured with a digital Vernier calliper. To measure minute foramina probes having diameter of 0.25 , 0.50 and $0.75 \mathrm{~mm}$ were used. Distance of foramen Vesalius from ipsilateral foramen ovale was measured as well. All the measurements were repeated twice to eliminate interobserver variation. The shape of the foramen was noted. The data was recorded in tabular form. The data was analysed with Microsoft Excel software. Comparison of maximum dimensions of foramen Vesalius was done on right and left sides of middle cranial fossa. Unpaired t-test was used.

\section{RESULTS}

Out of the thirty skulls examined, nine skulls showed the presence of foramen Vesalius (incidence being 30\%). Six skulls (20\%) showed bilateral foramen Vesalius, whereas in three skulls $(10 \%)$ the foramen was unilateral. The three unilateral foramina were on the left side. The results are tabulated in Table 1. All the foramina were patent and allowed a metallic probe to pass through. Figure 1 shows a skull with bilateral foramen Vesalius. Figure 2 shows a skull with unilateral foramen Vesalius. The mean maximum diameter of foramen Vesalius was found to be $1.13 \pm 0.30 \mathrm{~mm}$ on the right side and $1.38 \pm 0.33 \mathrm{~mm}$ on the left side. The diameters on the left side were more than the right side, but the difference was not found to be statistically significant by applying 'unpaired student t-test.' The average distance between foramen Vesalius and ipsilateral foramen ovale was measured to be $1.42 \pm 0.19 \mathrm{~mm}$ on the right side and $2.17 \pm 0.28 \mathrm{~mm}$ on the left side. The distances on left and right sides were different, but the difference was not statistically significant (unpaired student t-test was applied). The mean maximum diameter of the foramen is represented in Table 2 . The distance between foramen Vesalius and ipsilateral foramen ovale is represented in Table 3. No classification of foramen Vesalius according to its shape could be proposed in our study, as the shape of the foramina did not match any regular geometric shape. All the foramina in our study were more or less irregular.

\begin{tabular}{|c|c|c|c|}
\hline $\begin{array}{c}\text { Total } \\
\text { Number of } \\
\text { Skulls }\end{array}$ & $\begin{array}{c}\text { Number of } \\
\text { Skulls with } \\
\text { Foramen } \\
\text { Vesalius }\end{array}$ & $\begin{array}{c}\text { Number of } \\
\text { Skulls with } \\
\text { Bilateral } \\
\text { Foramen } \\
\text { Vesalius }\end{array}$ & $\begin{array}{c}\text { Number of } \\
\text { Skulls with } \\
\text { Unilateral } \\
\text { Foramen } \\
\text { Vesalius }\end{array}$ \\
\hline 30 & $9(30 \%)$ & $6(20 \%)$ & $3(10 \%)$ \\
\hline \multicolumn{3}{|c|}{ Table 1. (Table showing incidence of Foramen Vesalius) } \\
\hline
\end{tabular}

\begin{tabular}{|c|c|c|}
\hline $\begin{array}{c}\text { Mean Maximum } \\
\text { Diameter on Right } \\
\text { Side (mm) }\end{array}$ & $\begin{array}{c}\text { Mean Maximum } \\
\text { Diameter on Left } \\
\text { Side (mm) }\end{array}$ & P-value \\
\hline $1.13 \pm 0.30$ & $1.38 \pm 0.33$ & 0.01 \\
\hline Table 2. (Table showing Mean Maximum Diameter of \\
Foramen Vesalius) \\
\hline
\end{tabular}

\begin{tabular}{|c|c|c|}
\hline $\begin{array}{l}\text { Distance between } \\
\text { Foramen Vesalius } \\
\text { and Ipsilateral } \\
\text { Foramen Ovale on } \\
\text { Right Side (mm) }\end{array}$ & $\begin{array}{l}\text { Distance between } \\
\text { Foramen Vesalius } \\
\text { and Ipsilateral } \\
\text { Foramen Ovale on } \\
\text { Left Side (mm) }\end{array}$ & P-value \\
\hline $1.42 \pm 0.19$ & $2.17 \pm 0.28$ & 0.01 \\
\hline
\end{tabular}

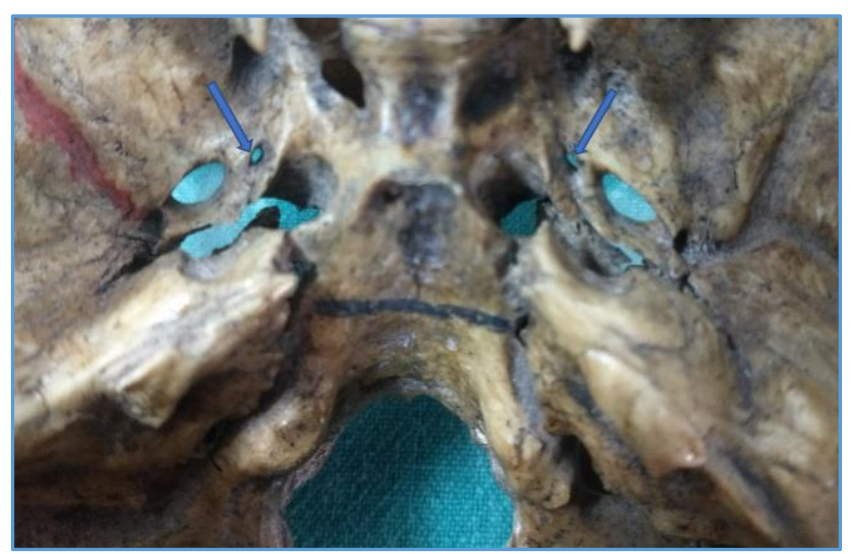

Figure 1. (Middle Cranial Fossa showing Bilateral Foramen Vesalius)

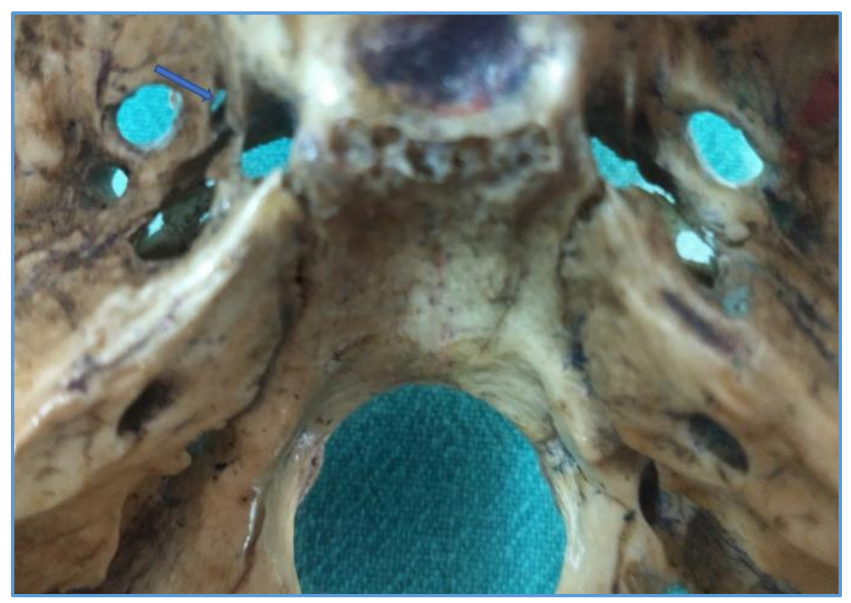

Figure 2. (Middle Cranial Fossa showing Unilateral Foramen Vesalius)

\section{DISCUSSION}

Foramen Vesalius is situated in the posterior part of greater wing of sphenoid. It was first described by the illustrious anatomist, Andreas Vesalius. Vesalius is widely hailed as the "Father of Modern Anatomy." He composed the most famous anatomic treatise of his time, "De humani corporis fabrica" and included his findings in it. Vesalius describes the foramen as follows- "because one skull is more elegant than the other, belonging to a man of middle age is by far the most handsome I have ever seen, displays the foramen."[5]

Most of the bones of skull base are preformed in cartilage. They ossify by the process of endochondral ossification with a small portion ossifying in membrane. At 11 weeks and 5 
days, the entire skull base is preformed in cartilage and then ossification proceeds from posterior to anterior part. Sphenoid bone is mainly ossified from pre- and postsphenoid centers with some contribution from alisphenoid and orbitosphenoid centers.[6] The post-sphenoid and presphenoid centers appear at 14 weeks and 17 weeks respectively.[6] The alisphenoid and orbitosphenoid centers appear during $15^{\text {th }}$ and $16^{\text {th }}$ week respectively.[6] The greater wings of sphenoid develop from alisphenoid centers. It has been proven that the foramen Vesalius represents the site of fusion between the two parts of sphenoid, which ossify in separate modes (membranous and cartilaginous).[6,7] Some authors opine that the foramen ovale may be subdivided into two compartments due to an ingrowing bony spicule. The ingrowing bristle divides the foramen ovale into anterior and posterior compartments. The anterior compartment thus formed is known as sphenoidal emissary foramen.[8] This foramen serves as an expression of differentiation of cranial venous outlet, that is characteristic in humans and does not occur in any other primates.

Various irregular grooves and inconstant foramina can be found in close proximity of foramen ovale. These inconstant patterns can be interpreted as arising from the interplay of the various parts of the membrane bones and the emissary venous plexus from pterygoid venous plexus to middle meningeal veins.[7] So the foramina of skull base are formed around pre-existing structures.[6]

Foramina in skull are very important, because they allow various neurovascular structures to pass through them. Apart from embryological causes, the presence of anomalous foramina can be variously attributed to diseases like osteoporosis, osteopetrosis and neurofibromatosis.[8] So the underlying causes can be inherited or acquired.

The current study has established an incidence of $30 \%$ for foramen Vesalius. In our study, $20 \%$ of the foramina were bilateral and $10 \%$ of the foramina were unilateral. Other authors have also reported this variation in various studies. Gupta et al[9] have reported an incidence of $34 \%$. In their study, $14 \%$ of the foramina are bilateral and $20 \%$ foramina are unilateral. Gupta et al[10] have reported an incidence of $32.85 \%$. They have found $22.85 \%$ of the foramina as bilateral and $10 \%$ of the foramina as unilateral. Kale et al[11] report the incidence of foramen Vesalius as $45 \%$. Kale and Associates have reported $25 \%$ bilateral foramina and $19.9 \%$ unilateral foramina in their study. Rossi et al[12] have found the incidence of foramen Vesalius as $40 \%$. Out of them $13.75 \%$ are bilateral and $26.5 \%$ are unilateral. Shinohara et al[13] have reported an incidence of $33.75 \%$. Shinohara and Associates have found $15.5 \%$ of the foramina as bilateral and $18.25 \%$ of the foramina as unilateral. Gray's mention an incidence of $40 \%$ for foramen Vesalius.[1] However Chaisuksant et al[14] and Singh et al[15] have reported sharply contrasting incidences of $10.9 \%$ and $51 \%$ respectively. The variable findings can be explained on the basis of regional, ethnic and racial variations.

We have found increased frequency of foramen ovale on the left side compared to the right side. Our findings match with that of Kale et al[11] and Shinohara et al.[13] Kale and Associates have found $10.37 \%$ foramina on the left side and 9.51\% foramina on the right side. Shinohara and Associates have found $10.5 \%$ foramina on the left side and $7.75 \%$ foramina on the right side. However, Rossi et al[12] have found increased frequency of foramen Vesalius on the right side. They have reported $15.62 \%$ foramina on the right side and $11.25 \%$ foramina on the left side.

Some authors ${ }^{[9,12,13]}$ report increased frequency of unilateral foramen Vesalius while others[10,11] report increased frequency of bilateral ones. However, Vesalius had described the unilateral incidence to be more frequent than the bilateral ones.[5]

Lanizieri et al[16] have established that foramen Vesalius is usually bilaterally symmetrical. They opine that asymmetry of foramen Vesalius is due to pathologic conditions like invasion by nasopharyngeal melanoma, angiofibroma and carotid-cavernous fistula with drainage through the sphenoidal emissary vein in foramen Vesalius.

Foramen Vesalius is very important in neurosurgical procedures, which cannulate foramen ovale. Cannulation of foramen ovale is done in percutaneous treatment of trigeminal neuralgia like trigeminal nerve radiofrequency rhizotomy, percutaneous balloon compression and glycerol injection. $[9,11,12,14]$ Foramen ovale is also cannulated in percutaneous biopsy of parasellar space-occupying lesions located in Meckel's trigeminal cave, cavernous sinus and petroclival region.[3] In such procedures, the needle may erroneously enter foramen Vesalius instead of the intended foramen ovale. This will puncture the cavernous sinus resulting in temporal lobe haematoma.[17,18] Sindou et al[3] have reported creation of false paths in 10 out of 200 such procedures; one in jugular foramen, two in carotid canal and seven in foramen Vesalius.

Therefore, the knowledge of presence of foramen Vesalius, its dimensions and location is not only important for anatomists but also for neurosurgeons. Such knowledge can prevent unwanted iatrogenic neurosurgical trauma.

The mean maximum diameter of foramen Vesalius was found to be $1.13 \pm 0.30 \mathrm{~mm}$ on right side and $1.38 \pm 0.33 \mathrm{~mm}$ on the left side in the current study. Rossi et al[12] have found the mean maximum diameter as $1.457 \pm 1.043 \mathrm{~mm}$ on right side and $1.592 \pm 0.938 \mathrm{~mm}$ on left side. Shinohara et al[13] have reported values of $0.67 \pm 0.28 \mathrm{~mm}$ on the right side and $0.76 \pm 0.39 \mathrm{~mm}$ on the left side. Chaisuksunt et al[14] have found the mean maximum diameter as $1.71 \pm 0.58 \mathrm{~mm}$ on the right side and $2.22 \pm 1.05 \mathrm{~mm}$ on the left side. Singh et al[15] have reported an average mean maximum diameter of foramen Vesalius as $0.79 \mathrm{~mm}$ on the right side and $0.96 \mathrm{~mm}$ on the left side. The average distance of foramen Vesalius from ipsilateral foramen ovale was determined to be $1.42 \pm 0.19 \mathrm{~mm}$ on the right side and $2.17 \pm 0.28 \mathrm{~mm}$ on the left side in the current study. Prakash et al[19] have reported the distance between foramen Vesalius and foramen ovale as $1.45 \pm 0.1 \mathrm{~mm}$ on the right side and $2.1 \pm 0.8 \mathrm{~mm}$ on the left side. The average distance between foramen Vesalius and foramen ovale has been reported as $2.63 \pm 1.24 \mathrm{~mm}$ by Lazarus et al.[20]

Knowledge of foramen Vesalius is also useful in interpreting CT and MRI of the skull.[8]

\section{CONCLUSION}

The foramen Vesalius is a common anatomical variation with an embryological basis to its formation. The findings of the 
study will be useful in anatomy, anthropology, general clinical practice, radiology and neurosurgery.

\section{REFERENCES}

[1] Standring S. Gray's Anatomy. 40th edn. London: Churchill Livingstone/ Elsevier 2008: p. 424-5.

[2] Freire AR, Rossi AC, Souza de Olivera VC, et al. Emissary foramens of the human skull: an anatomical characteristics and its relations with clinical neurosurgery. Int J Morphol 2013;31(1):287-92.

[3] Sindou M, Keravel Y, Abdennebi B, et al. Neurosurgical treatment of trigeminal neuralgia. Direct approach or percutaneous method? Neurochirugie 1987;33(2):89111.

[4] Sweet WH, Poletti CE. Complications of percutaneous rhizotomy and microvascular decompression operations for facial pain. In: Schmideck HH, Sweet $\mathrm{WH}$, eds. Operative neurosurgical techniques: indication, method and results. Ornaldo, FL: Grune and Stratton 1988: p. 1139-44.

[5] Hast MH, Garrison DH. Vesalius on variability of human skull: Book I, Chapter V of De humani corporis fabrica. Clin Anat 2000;13(5):311-20.

[6] Nemzek WR, Brodie HA, Hecht ST, et al. MR, CT and plain film imaging of developing skull base in fetal specimens. AJNR J Neuroradiol 2000;21(9):1699-706.

[7] James TM, Presley R, Steel FL. The foramen ovale and sphenoidal angle in man. Anat and Embryol (Berl) 1980;160(1):93-104.

[8] Jadhav SD, Ambali MP, Zambare BR. Sphenoidal emissary foramen and its clinical consideration. Int J Res Med Sci 2016;4(7):2926-9.

[9] Gupta N, Yadav A, Thomas RJ, et al. Incidence of foramen Vesalius in adult human North Indian crania. Journal of Dental and Medical Sciences 2014;13(5):348.
[10] Gupta N, Ray B, Ghosh S. Anatomical characteristics of foramen Vesalius. Kathmandu Univ Med J 2005;3(2):155-8.

[11] Kale A, Aksu F, Ozturk A, et al. Foramen of Vesalius. Saudi Med J 2009;30(1):56-9.

[12] Rossi AC, Freire AR, Prado FB, et al. Morphological characteristics of foramen of Vesalius and its relationship with clinical implications. J Morphol Sci 2010;27(1):26-9.

[13] Shinohara AL, De Souza Melo CG, Silveira EM, et al. Incidence, morphology and morphometry of foramen Vesalius: complimentary study for a safer planning and execution of trigeminal rhizotomy technique. Surg Radiol Anat 2010;32(2):159-64.

[14] Chaisuksunt V, Kwathai L, Namonta K, et al. Occurrence of the foramen of Vesalius and its morphometry relevant to clinical consideration. Article ID 817454, Scientific World Journal 2012;2012:1-5.

[15] Singh PR, Raibagkar CJ. Study of variation in atypical foramina of dry human skull. NJIRM 2011;2(2):1-5.

[16] Lanzieri CF, Duchesneau PM, Rosenbloom SA, et al. The significance of asymmetry of the foramen of Vesalius. AJNR Am J Neuroradiol 1988;9(6):1201-4.

[17] Gil A, Lopez-Ibor L, Lopez-Flores G, et al. Treatment of a carotid cavernous fistula via direct transovale cavernous sinus puncture. J Neurosurg 2013;119(1):247-51.

[18] Hakanson S. Trigeminal neuralgia treated by injection of glycerol into trigeminal cistern. Neurosurg 1981;9(6):633-46.

[19] Prakash KG, Viveka S. Morphometry and variations of foramen Vesalius: significance in surgical approach to mandibular nerve. Int J Anat Res 2015;3(4):1737-40.

[20] Lazarus L, Naidoo N, Satyapal KS. An osteometric evaluation of Foramen spinosum and Venosum. Int J Morphol 2015;33(2):452-8. 